\title{
Plant species richness regulates soil respiration through changes in productivity
}

\author{
André Tavares Corrêa Dias · Jasper van Ruijven • \\ Frank Berendse
}

Received: 19 August 2009/Accepted: 14 January 2010/Published online: 19 February 2010

(C) The Author(s) 2010. This article is published with open access at Springerlink.com

\begin{abstract}
Soil respiration is an important pathway of the $\mathrm{C}$ cycle. However, it is still poorly understood how changes in plant community diversity can affect this ecosystem process. Here we used a long-term experiment consisting of a gradient of grassland plant species richness to test for effects of diversity on soil respiration. We hypothesized that plant diversity could affect soil respiration in two ways. On the one hand, more diverse plant communities have been shown to promote plant productivity, which could increase soil respiration. On the other hand, the nutrient concentration in the biomass produced has been shown to decrease with diversity, which could counteract the production-induced increase in soil respiration. Our results clearly show that soil respiration increased with species richness. Detailed analysis revealed that this effect was not due to differences in species composition. In general, soil respiration in mixtures was higher than would be expected from the monocultures. Path analysis revealed that species richness predominantly regulates soil respiration through changes in productivity. No evidence
\end{abstract}

Communicated by Jason Kaye.

Electronic supplementary material The online version of this article (doi:10.1007/s00442-010-1569-5) contains supplementary material, which is available to authorized users.

A. T. C. Dias - J. van Ruijven - F. Berendse

Nature Conservation and Plant Ecology Group,

Wageningen University and Research Centre,

Droevendaalsesteeg 3a, 6708 PB Wageningen,

The Netherlands

\section{A. T. C. Dias $(\square)$}

Department of Animal Ecology, Institute of Ecological Science,

VU University Amsterdam, De Boelelaan 1085,

1081 HV Amsterdam, The Netherlands

e-mail: andre.dias@falw.vu.nl supporting the hypothesized negative effect of lower $\mathrm{N}$ concentration on soil respiration was found. We conclude that shifts in productivity are the main mechanism by which changes in plant diversity may affect soil respiration.

Keywords Biodiversity - Ecosystem functioning · Plant productivity $\cdot$ Soil carbon $\cdot$ Nitrogen content

\section{Introduction}

Changes in community composition and diversity can have important impacts on ecosystem functioning (Hooper et al. 2005; Spehn et al. 2005). Most of the studies investigating such effects focused on primary productivity and nutrient cycling as measures of ecosystem functioning. The effect of plant diversity on other important ecosystem processes remains poorly understood. Soil respiration is an important pathway of the global $\mathrm{C}$ cycle. It integrates root respiration and soil heterotrophic activity recycling soil $\mathrm{C}$ originating from litter, roots and root exudates (Raich and Tufekcioglu 2000). The annual C flux through soil respiration represents approximately $10 \%$ of the atmospheric C pool and is 10 times greater than that through fossil fuel combustion (Raich and Schlesinger 1992; Schlesinger and Andrews 2000). Therefore, changes in factors that control rates of soil respiration can have important impacts on atmospheric $\mathrm{CO}_{2}$ concentration.

The effects of plant diversity on soil respiration have been investigated by few experiments, which have yielded conflicting results. Both positive (Craine et al. 2001) and neutral relationships (De Boeck et al. 2007; Johnson et al. 2008) between plant diversity and soil respiration have been reported. Craine et al. (2001) proposed that the increase in productivity with increased diversity observed 
in the same experiment (Reich et al. 2001) could explain the positive effects of diversity on soil respiration that they reported. However, De Boeck et al. (2007) also reported a positive relationship between diversity and productivity, but they could not find any relationship between diversity and soil respiration. The multiple controls by which plant communities can affect soil respiration (Raich and Tufekcioglu 2000) suggest that a multi-factor approach may be necessary to get a better mechanistic understanding of how changes in plant diversity can affect this ecosystem process.

Plant diversity may affect soil respiration in several ways. The most important one is probably through changes in C input into the soil (Janssens et al. 2001; Raich and Tufekcioglu 2000). Diversity experiments with grassland species have shown that more diverse plant communities are often more productive (Hooper et al. 2005; Spehn et al. 2005), leading to increased $\mathrm{C}$ inputs. However, more diverse plant communities also showed higher $\mathrm{N}$ use efficiency, i.e. the $\mathrm{N}$ concentration in the biomass produced decreased (Fargione et al. 2007; van Ruijven and Berendse 2005). This reduction of the $\mathrm{N}$ concentration of organic matter may negatively affect both autotrophic and heterotrophic components of soil respiration. As plants with lower leaf and root $\mathrm{N}$ concentrations generally show lower root respiration per unit of biomass (Tjoelker et al. 2005), the increase in root respiration with increasing root biomass in more diverse communities could be (partly) counteracted by the negative effect of reduced $\mathrm{N}$ concentration on root respiration. In addition, lower $\mathrm{N}$ concentrations in leaf and root litter may restrict microbial respiration due to $\mathrm{N}$ limitation (Neely et al. 1991; Tewary et al. 1982). However, this decrease in the heterotrophic component of soil respiration is expected to only temporarily affect soil respiration, as it would be compensated for by increased overall respiration due to increased accumulation of soil organic matter. In the long run, this should lead to a steady state between input and output of soil organic C (Raich and Nadelhoffer 1989). Thus, reduced N concentration in more diverse communities can counteract the production-induced positive effect on soil respiration due to reduced root respiration per biomass unit and/or lower decomposition rates, but only if the experimental communities have not yet reached a steady state in terms of soil organic matter dynamics.

Here, we used a long-term plant diversity experiment to test how soil respiration is regulated by plant diversity. In this experiment the long-term persistence of a positive diversity-productivity relationship has been demonstrated (van Ruijven and Berendse 2003). We used path analysis to determine whether potential effects of species richness on soil respiration can be explained by changes in productivity and/or leaf $\mathrm{N}$ concentration.

\section{Materials and methods}

In early spring 2000, one hundred and two plots $\left(1 \mathrm{~m}^{2}\right)$ were established in a randomized block design on an arable field at the Wageningen University campus, The Netherlands. The topsoil was removed to a depth of $45 \mathrm{~cm}$. At this depth, the sand layer below the arable soil was reached. Square wooden frames measuring $1 \times 1 \times 0.5 \mathrm{~m}$ (length $\times$ width $\times$ height) were placed into each hole and filled with an arable field soil diluted with pure sand (1:3). The area outside the frames was filled with the arable soil. A total of 144 seedlings were planted per plot following a substitutive design in order to keep seedling density constant in all plots. Plots were distributed over six replicated blocks and each block contained monocultures of all species, mixtures of two, four and eight species. Species were selected from a pool of four grass species (Holcus lanatus L., Agrostis capillaris L., Festuca rubra L. and Anthoxanthum odoratum L.) and four forb species (Plantago lanceolata L., Rumex acetosa L., Leucanthemum vulgare Lam., and Centaurea jacea L.), that commonly coexist in European hay meadows. Mixtures of two and four species were assembled by constrained random selection from the above-mentioned species pool. Selecting the same composition twice was not allowed in this procedure. Species composition was maintained throughout the experiment by removing seedlings of all other species at monthly intervals during the growing season. Aboveground net primary productivity was measured by harvesting all aboveground plant material after species reached peak standing biomass. To avoid potential edge effects, the plots were divided into a centre of $60 \times 60 \mathrm{~cm}$ and a surrounding edge. Only data from the centres were used in the analyses. For more information, see van Ruijven and Berendse (2003).

In late July 2008, the plants were clipped $2.5 \mathrm{~cm}$ above soil surface, sorted to species and dried for at least $48 \mathrm{~h}$ at $70^{\circ} \mathrm{C}$ before weighing. Green leaves were collected at random from the biomass samples in order to determine $\mathrm{N}$ concentration. At least 20 leaves from each species in each plot were ground and digested using sulphuric acid, salicylic acid, hydrogen peroxide, and selenium. $\mathrm{N}$ concentration was measured colorimetrically using a segmented flow analyser (SKALAR SAN Plus System, Breda, The Netherlands). Soil respiration was measured once in every plot. Ideally, one would perform several measurements during the growing season to check for temporal variation, but clipping the vegetation during the growing season to provide the necessary plant-free patch for soil respiration measurements would have conflicted with the long-term maintenance of the experiment. Moreover, other studies using experimental plant communities have shown that temporal variation in soil respiration during the growing season is minimal (De Boeck et al. 2007; Johnson et al. 
2008). Thus, we are confident our measurements provide a good way to test for species richness effects on soil respiration within the growing season. However, caution must be taken when extrapolating the results to annual soil respiration, since large differences in phenology within the plant and the heterotrophic communities could lead to very different results. Soil respiration was measured in July within 2 weeks after harvest, when regrowth was still very limited. Measurements were done using a photo acoustic gas monitor (INNOVA 1412sn, 710-113; ENMO, Belgium) connected by Teflon tubes to a PVC chamber. The chamber was placed in the central position of the plot, directly onto the soil surface to a depth of $1 \mathrm{~cm}$. Before each measurement, the chamber was ventilated to prevent an accumulating $\mathrm{CO}_{2}$ concentration inside the chamber. Air samples were taken from the headspace of the closed, dark chamber (30 cm diameter, $25 \mathrm{~cm}$ height) every minute for $5 \mathrm{~min}$ for quantification of $\mathrm{CO}_{2}$. The flux was then calculated using linear regressions against time. Regressions provided a very good estimation of flux with $r^{2}$ ranging from 0.97 to 0.99 . Soil temperature and soil moisture content measurements were taken simultaneously at three points around the chamber. Soil temperature was measured at a depth of $10 \mathrm{~cm}$ using a soil thermometer (Eijkelkamp Agrisearch Equipment, Giesbeek) and soil moisture content was measured at 5-cm depth using a $\mathrm{HH} 2$ Delta-T device (Delta T Devices, Llandindrod Wells). For both soil temperature and soil moisture content, the average of the three measurements per plot were used in the analyses. The measurements were performed between 1000 and 1400 hours and their order was randomized within blocks. For each block, measurements were performed within 1 day, and 4 days were necessary to finish the measurements of all blocks.

The average leaf $\mathrm{N}$ concentration for a given community was calculated as a community functional parameter (Violle et al. 2007):

leaf $N_{\text {aggr. }}=\sum_{i=1}^{n} p_{i} \times$ leaf $N_{i}$

where leaf $N_{\text {aggr. }}$ is the community-aggregated value for leaf $\mathrm{N}$ concentration, $p_{i}$ is the relative abundance of species $i$ calculated as its proportion of total biomass in the plot, $n$ is the number of species in the mixture, leaf $N_{i}$ is the leaf $\mathrm{N}$ concentration for species $i$ in the mixture. As detailed information about biomass allocation to leaves and shifts in allocation with diversity is lacking for the different species in the experiment, we used the proportion of total biomass as an approximation for the relative abundance of species' leaves in mixtures.

In order to exclude variation in soil respiration due to soil temperature when calculating the expected values for species mixtures based on the monocultures, we calculated soil respiration at the standard temperature of $10^{\circ} \mathrm{C}$ with the equation provided by Lloyd and Taylor (1994):

$R=R_{10} e^{308.56\left(\frac{1}{56.02}-\frac{1}{T-227.13}\right)}$

where $R$ is the measured soil respiration, $R_{10}$ is the soil respiration at $10^{\circ} \mathrm{C}$ and $T$ is the measured soil temperature (K). To control for species composition, the observed values of soil respiration in the species mixtures were compared with the expected values based on the monocultures. The expected soil respiration at $10^{\circ} \mathrm{C}\left(E R_{10}\right)$ for a certain species mixture was calculated using a mass ratio approach as follows:

$E R_{10}=\sum_{i=1}^{n} p_{i} \times M R_{10 i}$

where $p_{i}$ is the relative abundance of species $i, n$ is the number of species in the mixture and $M R_{10 i}$ is the value of $R_{10}$ in monocultures for species $i$. Because of significant block effects for soil respiration, we used the $M R_{10 i}$ within blocks instead of the average $M R_{10 i}$ to generate the expected values. The difference between observed and expected values for $R_{10}$ was calculated as: $D_{R 10}=\ln$ (observed) $-\ln$ (expected).

General linear models (GLM) with block as a random factor and the $\log _{2}$ of species richness as a covariate were used to determine the relationships between species richness and soil respiration, $D_{R 10}$, biomass, leaf $N_{\text {aggr., }}$ soil temperature and soil moisture. For the analysis of soil respiration, soil temperature and moisture content were also included as covariates. Differences in leaf $\mathrm{N}$ concentration and soil respiration between species in monocultures were tested using GLM with block as a random factor and species identity as fixed factor. Leaf $\mathrm{N}$ concentration was log transformed to meet assumptions of homogeneity of variances. For the analysis of soil respiration, soil temperature and moisture content were included as covariates.

By decoupling direct and indirect effects, path analysis allows one to test for specific hypotheses regarding the relationships between multiple variables. We used path analysis to determine whether the relationship between plant diversity and soil respiration could be explained by changes in productivity and/or leaf $\mathrm{N}$ concentration. Eight alternative models were included to test our hypotheses (Fig. 1) following the approach suggested by Shipley (2004). The effects of diversity on productivity and $\mathrm{N}$ use efficiency have already been well described in the literature (Fargione et al. 2007; van Ruijven and Berendse 2005). Therefore, all models included an effect of species richness on productivity and leaf $N_{\text {aggr. }}$ We then designed models to test if species richness affects soil respiration through changes in productivity only (model A), leaf $N_{\text {aggr. }}$ only 

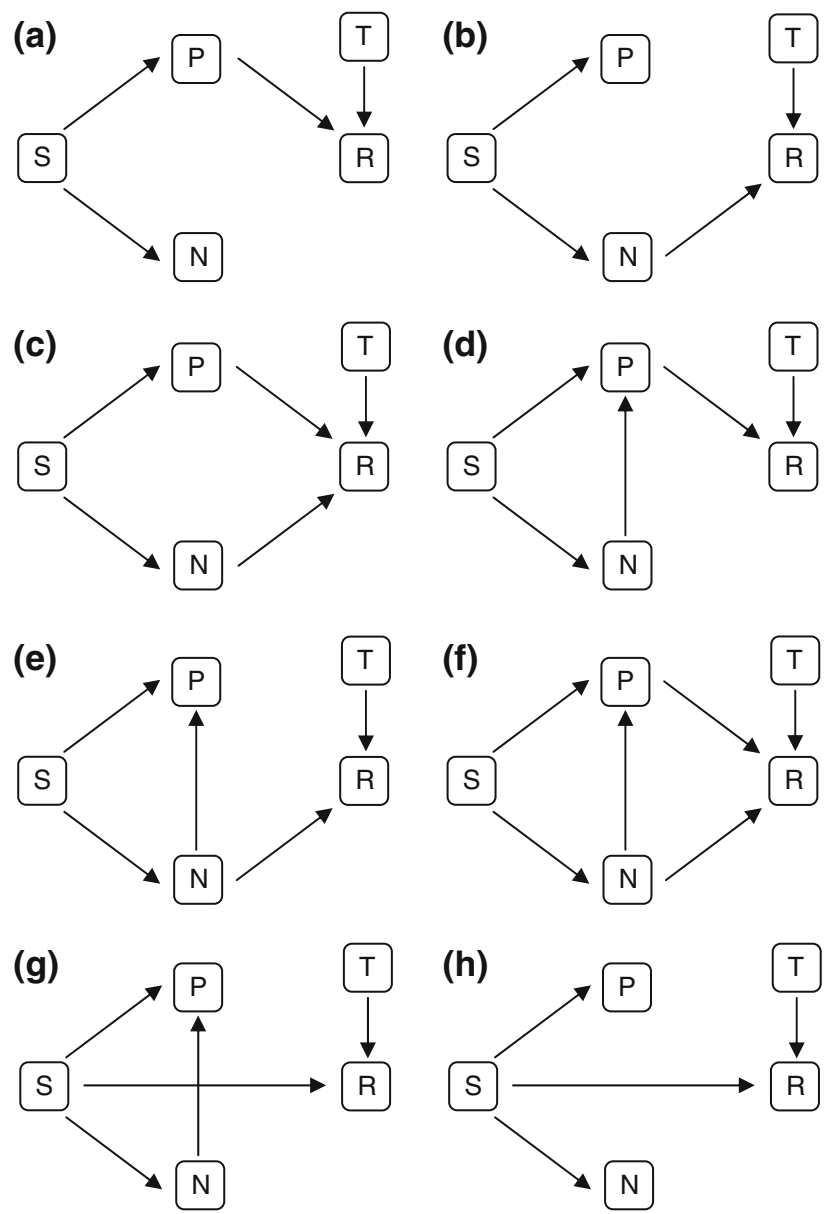

Fig. 1 Eight alternative hypotheses (models $\mathbf{a}, \mathbf{b}, \mathbf{c}, \mathbf{d}, \mathbf{e}, \mathbf{f}, \mathbf{g}$ and $\mathbf{h}$ ) describing relationships between species richness $(S)$, biomass $(P)$, community-aggregated value for leaf $\mathrm{N}$ concentration $(N)$, soil respiration $(R)$ and soil temperature $(T)$

(model B) or both (model C). Because $\mathrm{N}$ use efficiency has been suggested as a mechanism by which diversity affects productivity (Fargione et al. 2007; van Ruijven and Berendse 2005), we included an effect of leaf $N_{\text {aggr. }}$ on productivity and then tested again if species richness affects soil respiration through changes in productivity only (model D), leaf $N_{\text {aggr. }}$ only (model E) or both (model F). Finally, we tested whether species richness had a direct effect on soil respiration (i.e. determined by mechanisms not specified in the model) using models that either include the effect of leaf $N_{\text {aggr. }}$ on productivity (model G) or not (model H). Soil moisture did not show significant effects on soil respiration and was not included in the models. The direct effect of soil temperature on soil respiration was included in all models (Fig. 1).

Path models are often tested with maximum likelihood $\chi^{2}$ statistics, which require large number of replicates and multivariate normality. Because these assumptions are often difficult to meet with ecological data, we tested the path models with the d-sep test (Shipley 2000). This method tests the statistical constraints imposed by the model, which are in the form of conditional independence relationships. For example, if we state that species richness (S) affects soil respiration $(\mathrm{R})$ through increasing productivity $(\mathrm{P})$ only, $\mathrm{S}$ and $\mathrm{R}$ should be independent when $\mathrm{P}$ is held constant statistically. In other words, $\mathrm{S}$ and $\mathrm{R}$ are independent conditional to P. Here, we measured independence using Pearson (partial) correlations, where no significant (partial) correlation corroborates the stated independence relationship. For each model, the implied separate tests of independence $\left(p_{i}\right)$ were combined using the Fisher's $C$ statistic to provide a test for the entire model:

$C=-2 \sum_{i=1}^{n} \ln \left(p_{i}\right)$

where $n$ is the number of tests of independence and $C$ is distributed as a $\chi^{2}$ variable with $2 n d f$. For the accepted model, relationships between variables were determined using simple or multiple regressions. The $\beta$ coefficients (i.e. regression coefficients obtained for variables standardized to a mean of 0 and a SD of 1) were used to indicate the relationship between variables. All variables were $\ln$-transformed in order to improve the linearity of relationships.

\section{Results}

Soil respiration showed a significant positive relationship with species richness $\left(F_{1,92}=8.66, P=0.004\right.$; Fig. $\left.2 a\right)$. We found significant differences in soil respiration between species monocultures $\left(F_{7,31}=2.97, P=0.017\right.$; Fig. 3a), but differences were not related to plant functional type (i.e. grasses or forbs). When biomass was included as a covariate in this analysis it showed a significant positive relationship with soil respiration $\left(F_{1,30}=10.20, \quad P=0.003\right)$, but monoculture identity remained significant $\left(F_{7,30}=3.10, P=0.014\right)$. Leaf $\mathrm{N}$ concentration also differed significantly different between species in monocultures $\left(F_{7,32}=8.02, \quad P<0.001\right.$; Fig. 3b), but leaf $\mathrm{N}$ concentration was not related to plant functional type or soil respiration $\left(r_{\text {pearson }}=-0.19\right.$, $n=46, P=0.20$ ).

$D_{R 10}$ values were significantly higher then zero (grand mean $\pm \mathrm{SE}=0.146 \pm 0.04$ ), indicating that $R_{10}$ values in the mixtures were higher than expected based on monocultures. Although the $D_{R 10}$ values showed a trend to increase with species richness, this relationship was not significant $\left(F_{1.48}=1.00, P=0.32\right.$; Fig. $\left.2 b\right)$. Soil temperature ranged from 17 to $25^{\circ} \mathrm{C}$ and had a marginally significant positive effect on soil respiration $\left(F_{1,92}=3.40\right.$, $P=0.068)$. Soil moisture content varied between 10 and $24 \%$, but had no effect on soil respiration $\left(F_{1,92}=0.78\right.$, 

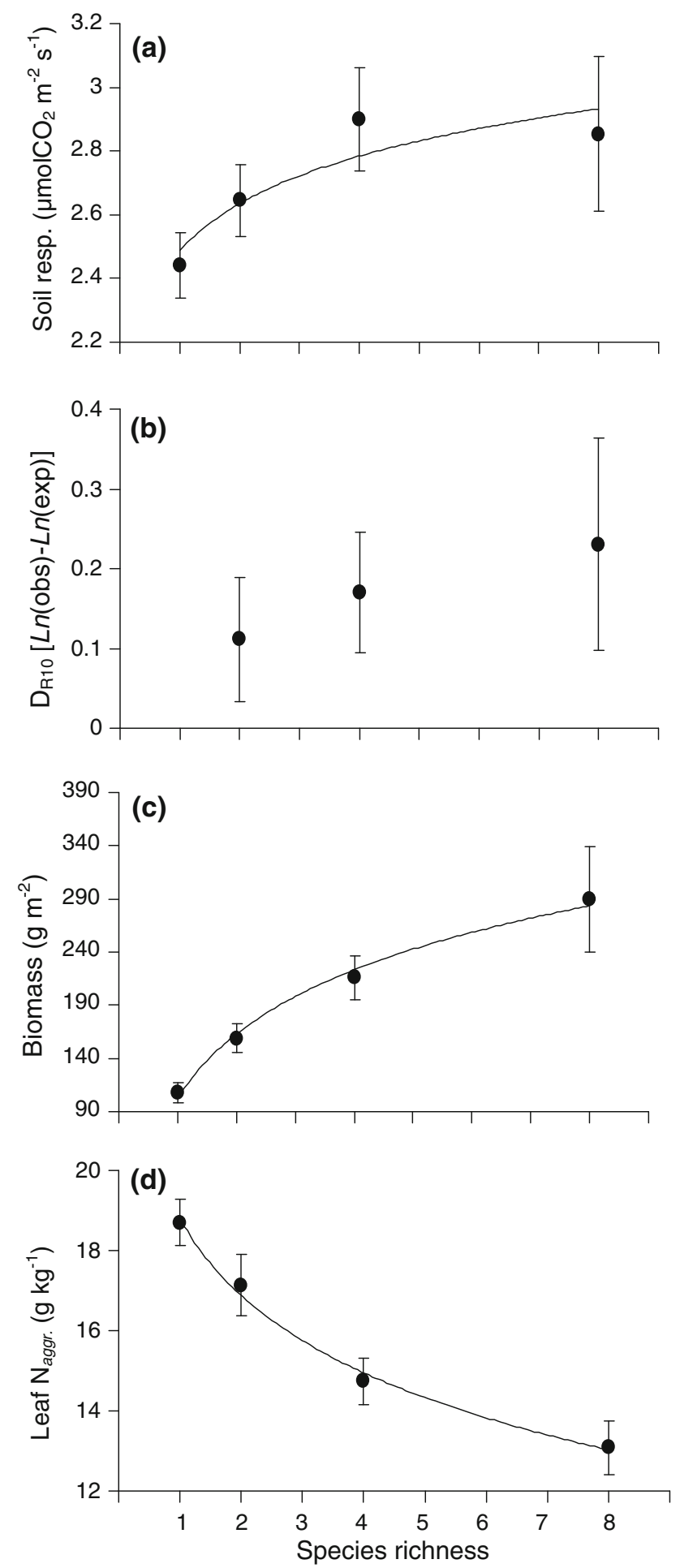

Fig. 2 Relationships between species richness and a soil respiration, b deviation from expected soil respiration based on monocultures $\left(D_{R 10}\right)$, c aboveground biomass, and $\mathbf{d}$ average community leaf $\mathrm{N}$ concentration $\left(N_{\text {aggr. }}\right)$. Except for $D_{R 10}$, each of the variables showed a significant relationship with species richness. See text for details. Means \pm SEs are shown
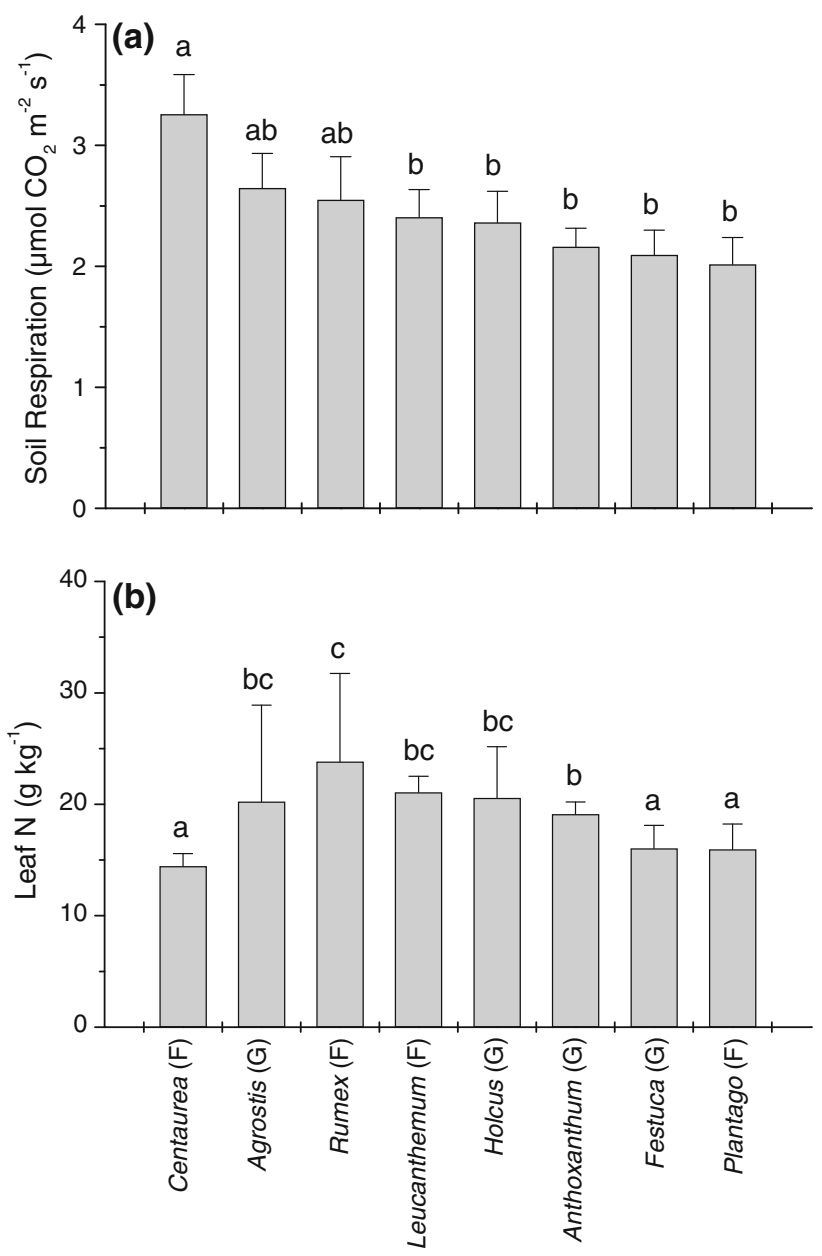

Fig. 3 Soil respiration and leaf $\mathrm{N}$ concentration for each species in monocultures (mean $\pm \mathrm{SE}$ ). Different letters denote significant $(P<0.05)$ differences between species (Tukey honest significant difference test). $G$ Grasses, $F$ forbs

$P=0.38$ ). Neither soil temperature nor soil moisture showed a significant relationship with species richness $\left(F_{1,94}=0.79, \quad P=0.38\right.$ and $F_{1,94}=2.6, \quad P=0.11$, respectively). Finally, aboveground plant biomass strongly increased with species richness $\left(F_{1,94}=47.32, P<0.001\right.$; Fig. 2c), whereas leaf $N_{\text {aggr. }}$ clearly decreased with species richness $\left(F_{1,94}=27.23, P<0.001\right.$; Fig. 2 d $)$. The latter was also shown by each species individually (data not shown).

Path analysis showed that the probability that the causal relationships hypothesized by models $\mathrm{A}, \mathrm{B}, \mathrm{C}, \mathrm{E}, \mathrm{G}$ and $\mathrm{H}$ actually generated the observed data was lower than 0.05 . These models were therefore rejected. On the other hand, there was a high probability that the causal processes hypothesized by both models $\mathrm{D}$ and $\mathrm{F}$ generated the observed data, 0.89 and 0.77 , respectively. However, the 


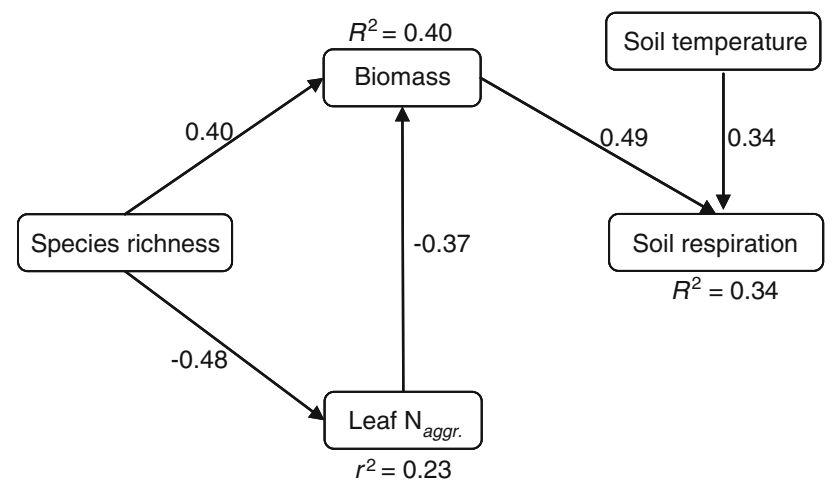

Fig. 4 Accepted path model (model D; Fisher's $C=5.01, d f=10$, $P=0.890$ ). It shows that species richness affects soil respiration through changes in biomass and that species richness affects biomass production both directly and indirectly through changes in $\mathrm{N}$ use efficiency. $\beta$ and determination coefficients from the regression analyses between variables are shown. For all coefficients, $P<0.001$

effect of leaf $N_{\text {aggr. }}$ on soil respiration hypothesized by model $\mathrm{F}$ was not significant ( $\beta$ coefficient $0.01, P=0.91$ ). Accordingly, model $\mathrm{D}$ also showed that soil respiration is independent of leaf $N_{\text {aggr. }}$ when other variables were controlled for. Therefore, only model D was accepted (Fig. 4).
See Table 1 for the complete set of individual claims of conditional independence implied by the models. Model D indicates that species richness affects soil respiration indirectly, through changes in productivity (Fig. 5). Furthermore, the estimated direct effect of species richness on biomass ( $\beta$ coefficient 0.40 ) was higher than the indirect effect through changes in leaf $N_{\text {aggr. }}$ (obtained by multiplying $\beta$ coefficients $-0.48 \times-0.37=0.18$; Fig. 4 ). The correlation matrix for the variables included in the model can be seen in the electronic supplemental material.

\section{Discussion}

Our results show that species richness predominantly regulates soil respiration through changes in productivity. This is in accordance with the model proposed by Raich and Nadelhoffer (1989), indicating that the increase in aboveground production implied an increase in total root $\mathrm{C}$ allocation (root production plus root respiration). We also hypothesized that lower leaf $\mathrm{N}$ concentrations observed in more diverse communities could counteract effects of productivity, because of their potentially negative effects on root and microbial respiration (Neely et al. 1991;

Table 1 Basis sets for the partial independence constraints implied by each of the five alternative models.

\begin{tabular}{|c|c|c|c|c|c|c|c|}
\hline \multicolumn{2}{|l|}{ Model A } & \multicolumn{2}{|l|}{ Model B } & \multicolumn{2}{|l|}{ Model C } & \multicolumn{2}{|l|}{ Model D } \\
\hline Basis set & $r(P)$ & Basis set & $r(P)$ & Basis set & $r(P)$ & Basis set & $r(P)$ \\
\hline$(\mathrm{S}, \mathrm{T}) \mid\{\varnothing\}$ & $-0.03(0.721)$ & $(\mathrm{S}, \mathrm{T}) \mid\{\varnothing\}$ & $-0.03(0.721)$ & $(\mathrm{S}, \mathrm{T}) \mid\{\varnothing\}$ & $-0.03(0.721)$ & $(\mathrm{S}, \mathrm{T}) \mid\{\varnothing\}$ & $-0.03(0.721)$ \\
\hline$(\mathrm{S}, \mathrm{R}) \mid\{\mathrm{T}, \mathrm{P}\}$ & $-0.02(0.851)$ & $(\mathrm{S}, \mathrm{R}) \mid\{\mathrm{T}, \mathrm{N}\}$ & $0.17(0.090)$ & $(\mathrm{S}, \mathrm{R}) \mid\{\mathrm{T}, \mathrm{P}, \mathrm{N}\}$ & $-0.02(0.869)$ & $(\mathrm{S}, \mathrm{R}) \mid\{\mathrm{T}, \mathrm{P}\}$ & $-0.02(0.851)$ \\
\hline$(\mathrm{T}, \mathrm{P}) \mid\{\mathrm{S}\}$ & $-0.03(0.792)$ & $(\mathrm{T}, \mathrm{P}) \mid\{\mathrm{S}\}$ & $-0.03(0.792)$ & $(\mathrm{T}, \mathrm{P}) \mid\{\mathrm{S}\}$ & $-0.03(0.792)$ & $(\mathrm{T}, \mathrm{P}) \mid\{\mathrm{S}, \mathrm{N}\}$ & $-0.07(0.468)$ \\
\hline$(\mathrm{T}, \mathrm{N}) \mid\{\mathrm{S}\}$ & $-0.11(0.301)$ & $(\mathrm{T}, \mathrm{N}) \mid\{\mathrm{S}\}$ & $-0.11(0.301)$ & $(\mathrm{T}, \mathrm{N}) \mid\{\mathrm{S}\}$ & $-0.11(0.301)$ & $(\mathrm{T}, \mathrm{N}) \mid\{\mathrm{S}\}$ & $-0.11(0.301)$ \\
\hline$(\mathrm{P}, \mathrm{N}) \mid\{\mathrm{S}\}$ & $-0.39(<\mathbf{0 . 0 0 1})$ & $(\mathrm{P}, \mathrm{N}) \mid\{\mathrm{S}\}$ & $-0.39(<\mathbf{0 . 0 0 1})$ & $(\mathrm{P}, \mathrm{N}) \mid\{\mathrm{S}\}$ & $-0.39(<\mathbf{0 . 0 0 1})$ & $(\mathrm{N}, \mathrm{R}) \mid\{\mathrm{S}, \mathrm{T}, \mathrm{P}\}$ & $0.01(0.947)$ \\
\hline$(\mathrm{N}, \mathrm{R}) \mid\{\mathrm{S}, \mathrm{T}, \mathrm{P}\}$ & $0.01(0.947)$ & $(\mathrm{P}, \mathrm{R}) \mid\{\mathrm{S}, \mathrm{T}, \mathrm{N}\}$ & $0.42(<\mathbf{0 . 0 0 1})$ & & & & \\
\hline \multicolumn{2}{|c|}{$12 d f, C=23.69(\mathbf{0 . 0 2 2})$} & \multicolumn{2}{|c|}{$12 d f, C=50.29(<\mathbf{0 . 0 0 1})$} & \multicolumn{2}{|c|}{$10 d f, C=23.54(\mathbf{0 . 0 0 9})$} & \multicolumn{2}{|c|}{$10 d f, C=5.01(0.890)$} \\
\hline \multicolumn{2}{|l|}{ Model E } & \multicolumn{2}{|l|}{ Model F } & \multicolumn{2}{|l|}{ Model G } & \multicolumn{2}{|l|}{ Model H } \\
\hline Basis set & $r(P)$ & Basis set & $r(P)$ & Basis set & $r(P)$ & Basis set & $r(P)$ \\
\hline$(\mathrm{S}, \mathrm{T}) \mid\{\varnothing\}$ & $-0.03(0.721)$ & $(\mathrm{S}, \mathrm{T}) \mid\{\varnothing\}$ & $-0.03(0.721)$ & $(\mathrm{S}, \mathrm{T}) \mid\{\varnothing\}$ & $-0.03(0.721)$ & $(\mathrm{S}, \mathrm{T}) \mid\{\varnothing\}$ & $-0.03(0.721)$ \\
\hline$(\mathrm{S}, \mathrm{R}) \mid\{\mathrm{T}, \mathrm{N}\}$ & $0.17(0.090)$ & $(\mathrm{S}, \mathrm{R}) \mid\{\mathrm{T}, \mathrm{P}, \mathrm{N}\}$ & $-0.02(0.869)$ & $(\mathrm{T}, \mathrm{P}) \mid\{\mathrm{S}, \mathrm{N}\}$ & $-0.07(0.468)$ & $(\mathrm{T}, \mathrm{P}) \mid\{\mathrm{S}\}$ & $-0.03(0.792)$ \\
\hline$(\mathrm{T}, \mathrm{P}) \mid\{\mathrm{S}, \mathrm{N}\}$ & $-0.07(0.468)$ & $(\mathrm{T}, \mathrm{P}) \mid\{\mathrm{S}, \mathrm{N}\}$ & $-0.07(0.468)$ & $(\mathrm{T}, \mathrm{N}) \mid\{\mathrm{S}\}$ & $-0.11(0.301)$ & $(\mathrm{T}, \mathrm{N}) \mid\{\mathrm{S}\}$ & $-0.11(0.301)$ \\
\hline$(\mathrm{T}, \mathrm{N}) \mid\{\mathrm{S}\}$ & $-0.11(0.301)$ & $(\mathrm{T}, \mathrm{N}) \mid\{\mathrm{S}\}$ & $-0.11(0.301)$ & $(\mathrm{P}, \mathrm{R}) \mid\{\mathrm{S}, \mathrm{T}, \mathrm{N}\}$ & $0.42(<\mathbf{0 . 0 0 1})$ & $(\mathrm{P}, \mathrm{N}) \mid\{\mathrm{S}\}$ & $-0.39(<\mathbf{0 . 0 0 1})$ \\
\hline \multirow[t]{2}{*}{$(\mathrm{P}, \mathrm{R}) \mid\{\mathrm{S}, \mathrm{T}, \mathrm{N}\}$} & $0.42(<\mathbf{0 . 0 0 1})$ & & & $(\mathrm{N}, \mathrm{R}) \mid\{\mathrm{S}, \mathrm{T}\}$ & $-0.17(0.092)$ & $(\mathrm{P}, \mathrm{R}) \mid\{\mathrm{S}, \mathrm{T}\}$ & $0.45(<\mathbf{0 . 0 0 1})$ \\
\hline & & & & & & $(\mathrm{N}, \mathrm{R}) \mid\{\mathrm{S}, \mathrm{T}\}$ & $-0.17(0.092)$ \\
\hline \multicolumn{2}{|c|}{$10 d f, C=31.62(<\mathbf{0 . 0 0 1})$} & \multicolumn{2}{|c|}{$8 d f, C=4.86(0.772)$} & \multicolumn{2}{|c|}{$10 d f, C=31.59(<\mathbf{0 . 0 0 1})$} & \multicolumn{2}{|c|}{$12 d f, C=53.64(<\mathbf{0 . 0 0 1})$} \\
\hline
\end{tabular}

The hypothesized relationship among variables can be seen in Fig. 1. $S$ Species richness, $T$ soil temperature, $P$ biomass, $N$ average community leaf $\mathrm{N}$ concentration, $R$ soil respiration

The notation $(\mathrm{X}, \mathrm{Y}) \mid\{\mathrm{A}, \mathrm{B}, \ldots\}$ means that variables $x$ and $y$ are hypothesized to be probabilistically independent conditional on the set of variables $\{\mathrm{A}, \mathrm{B}, \ldots\} . \varnothing$ represents the null (empty) set. Pearson's partial correlation coefficient $(r)$, and $P$ (assuming the null hypothesis) in parentheses, are given for each conditional independence claim; the overall model is tested with Fisher's $C$ statistic

$P<0.05$ indicated in bold, rejecting the hypothesized independence relationship 


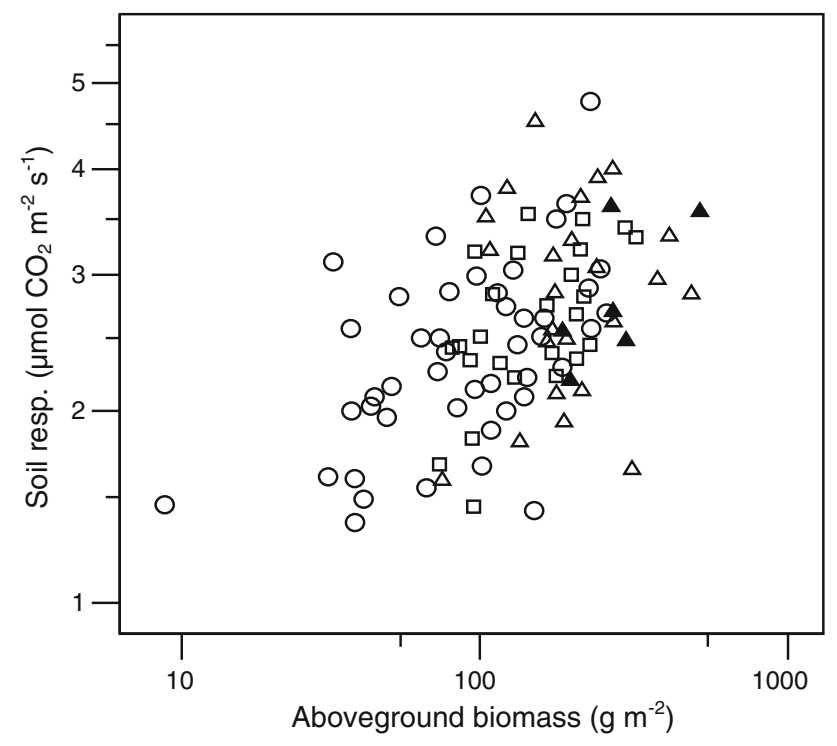

Fig. 5 Relationship between soil respiration and biomass. $\beta$ coefficient $=0.49, P<0.001$. Circles Monocultures, squares two-species plots, open triangles four-species plots, closed triangles eight-species plots. Note: $\log$ scale

Tewary et al. 1982; Tjoelker et al. 2005). However, soil respiration was independent of leaf $\mathrm{N}_{\text {aggr. }}$, indicating no direct effect of the quality of the organic matter produced on soil respiration. In our experiment, biomass and leaf $\mathrm{N}$ concentration were closely correlated, i.e. plots with lower leaf $\mathrm{N}$ concentration also had higher biomass production and consequently higher $\mathrm{C}$ input into the soil. We cannot rule out that the effects of increased biomass and decreased $\mathrm{N}$ content operated simultaneously, but the lack of a relationship between soil respiration and leaf $N_{\text {aggr. }}$ indicates that, if present, the effect of organic matter quality was not strong enough to counteract the increase in soil respiration due to increased biomass input.

The values of soil respiration presented here, ranging from 1.4 to $4.8 \mu \mathrm{mol} \mathrm{CO} \mathrm{C} \mathrm{m}^{-2} \mathrm{~s}^{-1}$, are at the lower range for grassland communities, but similar in magnitude to the values in other experiments with artificially assembled grassland communities in which aboveground biomass was also harvested annually (De Boeck et al. 2007; Johnson et al. 2008). Although aboveground biomass is annually removed from the experimental plots, it turned out to be a good surrogate for the input of $\mathrm{C}$ into the soil, representing the main driver of soil respiration in this experiment. Accordingly, aboveground biomass can be taken as a good indicator of belowground biomass in our experiment, as shown by root biomass samples from a subset of the plots. These data showed that root biomass in four-species mixtures was up to $40 \%$ higher than expected based on the component monocultures (J. van Ruijven and L. Mommer, unpublished data).
The comparison between observed values in species mixtures and expected values based on monocultures revealed that soil respiration in mixed species plots was higher than would be expected based on monoculture values. However, the difference between observed and expected values for mixed species plots was not correlated with species richness. In addition, the species with the highest soil respiration rates in monoculture, Centaurea jacea, showed higher rates than the most diverse mixtures; 3.3 and $2.9 \mu \mathrm{mol} \mathrm{CO}_{2} \mathrm{~m}^{-2} \mathrm{~s}^{-1}$, respectively. This could indicate that soil respiration is mainly driven by the presence of a particular species, i.e. a selection effect. Unfortunately, we could not partition the positive effect of diversity on soil respiration into its two components, selection and complementarity effects (Loreau and Hector 2001), because the species' relative contribution to soil respiration in mixtures could not be determined. However, it has previously been shown that the long-term persistence of the positive diversity-productivity relationship found in this experiment is due to complementarity effects, while selection effects are negligible (van Ruijven and Berendse 2003). Moreover, in an additional analysis the relationship between biomass and soil respiration was still significant $\left(F_{1,93}=17.4 ; P<0.001\right)$ when the presence of Centaurea was included as a covariate, while the latter showed no significant effect $\left(F_{1,93}=0.86\right.$; $P=0.356)$. Therefore, we conclude that, although species clearly differ in their effect on soil respiration, the positive relationship between species richness and soil respiration is due to an increase in biomass driven by complementarity effects.

We have shown that species richness predominantly affects soil respiration through an increase in productivity. This is consistent with Craine et al. (2001), who showed a significant positive relationship between soil respiration and species richness and Zak et al. (2003), who demonstrated that the positive relationship observed between microbial respiration and plant diversity is caused by an increase in productivity. However, plant diversity can also affect other ecosystem properties that may affect soil respiration in different ways. Two other experiments that investigated the effects of plant diversity on soil respiration did not find effects of species richness or productivity on soil respiration (De Boeck et al. 2007; Johnson et al. 2008). De Boeck et al. (2007) argued that the lower soil water contents found in more diverse communities in their experiment could counteract any possible productioninduced stimulation of soil respiration, whereas Johnson et al. (2008) hypothesized that the lack of interaction between sedges and mycorrhizal fungi was responsible for the reduced soil respiration observed in their experiment, suggesting that plant-species effects on soil respiration are possibly due to other mechanisms than those of biomass 
production. The circumstances under which these other controls can counteract production-induced stimulation of soil respiration remain to be determined.

The increase in $\mathrm{N}$ use efficiency with increasing diversity has been proposed as a mechanism of diversity effects on productivity (Fargione et al. 2007; van Ruijven and Berendse 2005). Specifically van Ruijven and Berendse (2005) hypothesized that the increase in biomass produced per unit $\mathrm{N}$ with increasing species richness was caused by increased allocation to stems due to increased light competition. We show that a shift in the leaf to stem ratio is not the only explanation for higher nutrient use efficiency in more diverse communities, as leaf $\mathrm{N}$ concentration also decreased with increasing species richness. The rejection of models $\mathrm{A}, \mathrm{B}, \mathrm{C}$ and $\mathrm{H}$ confirmed that species richness affects biomass production both through changes in nutrient use efficiency and through mechanisms not incorporated into our models, such as resource use complementarity leading to $\mathrm{N}$ overyielding (van $\mathrm{Ru}-$ ijven and Berendse 2005). The effect of species richness on productivity through changes in nutrient use efficiency represented $30 \%$ of the total effect of species richness on productivity. Our results thus confirm that this mechanism, which has only recently been proposed (van Ruijven and Berendse 2005), can play an important role in determining higher productivity in more diverse communities.

Traditionally, the $\mathrm{C}$ cycle has been addressed independently of the species involved, but recently several studies have shown that both plant species diversity and composition can have important impacts on $\mathrm{C}$ dynamics (Fornara and Tilman 2008; Schulze 2006; Steinbeiss et al. 2008). A detailed mechanistic understanding of biotic controls of soil respiration is needed in order to improve models of $\mathrm{CO}_{2}$ exchange between ecosystems and the atmosphere and consequently provide better predictions of how human impacts (i.e. land-use change, species extinction and introduction) on natural and semi-natural communities can affect $\mathrm{CO}_{2}$ fluxes. We conclude that shifts in productivity caused by changes in diversity can have a strong effect on soil respiration in grasslands. Studies in other ecosystems and of other possible drivers of soil respiration that can be affected by both plant species diversity and composition deserve further attention.

Acknowledgments We would like to thank Liesje Mommer for stimulating discussions and Jan van Walsem for practical assistance with leaf $\mathrm{N}$ measurements. Christian Körner, Jason Kaye, Daniel Laughlin and an anonymous reviewer provided valuable comments on an earlier draft of this manuscript. A. T. C. Dias received a grant from the C. T. de Wit Graduate School for Production Ecology and Resource Conservation (PE and RC). The plant diversity experiment was funded by the Dutch Organisation for Scientific Research (NWO) within the framework of the Stimulation Programme Biodiversity.
Open Access This article is distributed under the terms of the Creative Commons Attribution Noncommercial License which permits any noncommercial use, distribution, and reproduction in any medium, provided the original author(s) and source are credited.

\section{References}

Reich et al (2001) Plant diversity enhances ecosystem responses to elevated $\mathrm{CO}_{2}$ and nitrogen deposition. Nature 411:824-826

Craine JM, Wedin DA, Reich PB (2001) The response of soil $\mathrm{CO}_{2}$ flux to changes in atmospheric $\mathrm{CO}_{2}$, nitrogen supply and plant diversity. Glob Chang Biol 7:947-953

De Boeck HJ et al (2007) How do climate warming and species richness affect $\mathrm{CO}_{2}$ fluxes in experimental grasslands? New Phytol 175:512-522

Fargione J et al (2007) From selection to complementarity: shifts in the causes of biodiversity-productivity relationships in a longterm biodiversity experiment. Proc R Soc Lond B Biol Sci 274:871-876

Fornara DA, Tilman D (2008) Plant functional composition influences rates of soil carbon and nitrogen accumulation. J Ecol 96:314-322

Hooper DU et al (2005) Effects of biodiversity on ecosystem functioning: a consensus of current knowledge. Ecol Monogr 75:3-35

Janssens IA et al (2001) Productivity overshadows temperature in determining soil and ecosystem respiration across European forests. Glob Chang Biol 7:269-278

Johnson D, Phoenix GK, Grime JP (2008) Plant community composition, not diversity, regulates soil respiration in grasslands. Biol Lett 4:345-348

Lloyd J, Taylor JA (1994) On the temperature-dependence of soil respiration. Funct Ecol 8:315-323

Loreau M, Hector A (2001) Partitioning selection and complementarity in biodiversity experiments. Nature 412:72-76

Neely CL, Beare MH, Hargrove WL, Coleman DC (1991) Relationships between fungal and bacterial substrate-induced respiration, biomass and plant residue decomposition. Soil Biol Biochem 23:947-954

Raich JW, Nadelhoffer KJ (1989) Belowground carbon allocation in forest ecosystems: global trends. Ecology 70:1346-1354

Raich JW, Schlesinger WH (1992) The global carbon dioxide flux in soil respiration and its relationship to vegetation and climate. Tellus 44B:81-99

Raich JW, Tufekcioglu A (2000) Vegetation and soil respiration: correlations and controls. Biogeochemistry 48:71-90

Schlesinger WH, Andrews JA (2000) Soil respiration and the global carbon cycle. Biogeochemistry 48:7-20

Schulze ED (2006) Biological control of the terrestrial carbon sink. Biogeosciences 3:147-166

Shipley B (2000) A new inferential test for path models based on directed acyclic graphs. Struct Equ Model 7:206-218

Shipley B (2004) Analysing the allometry of multiple interacting traits. Perspect Plant Ecol Evol Syst 6:235-241

Spehn EM et al (2005) Ecosystem effects of biodiversity manipulations in European grasslands. Ecol Monogr 75:37-63

Steinbeiss S et al (2008) Plant diversity positively affects short-term soil carbon storage in experimental grasslands. Glob Chang Biol 14:2937-2949

Tewary CK, Pandey U, Singh JS (1982) Soil and litter respiration rates in different microhabitats of a mixed oak conifer forest and 
their control by edaphic conditions and substrate quality. Plant Soil 65:233-238

Tjoelker MG, Craine JM, Wedin D, Reich PB, Tilman D (2005) Linking leaf and root trait syndromes among 39 grassland and savannah species. New Phytol 167:493-508

van Ruijven J, Berendse F (2003) Positive effects of plant species diversity on productivity in the absence of legumes. Ecol Lett 6:170-175 van Ruijven J, Berendse F (2005) Diversity-productivity relationships: initial effects, long-term patterns, and underlying mechanisms. Proc Natl Acad Sci USA 102:695-700

Violle C et al (2007) Let the concept of trait be functional! Oikos 116:882-892

Zak DR, Holmes WE, White DC, Peacock AD, Tilman D (2003) Plant diversity, soil microbial communities, and ecosystem function: are there any links? Ecology 84:2042-2050 